\title{
VIRTUAL TOUR 3D SITUS PURBAKALA PUGUNG RAHARJO LAMPUNG TIMUR
}

\author{
Puput Budi Wintoro1, Irwan Irmawan², Deny Budiyanto3, \\ Rio Ariestia Pradipta 4 \\ Universitas Lampung $1,3,4$ \\ Jl. Prof. Dr. Ir. Sumantri Brojonegoro, RW.No: 1, Gedong Meneng, Kec. Rajabasa, \\ Kota Bandar Lampung, Lampung 35141, Telp (0721) 701609 \\ Institut Informatika dan Bisnis Darmajaya ${ }^{2}$ \\ Jl. Zainal Abidin Pagar Alam No. 93, Bandar Lampung - Indonesia 35142 \\ Telp. (0721) 787214 Fax. (0721) 700261 \\ budi.wintoro@eng.unila.ac.id1, irwanirmawan1996@gmail.com², \\ deny.budianto@eng.unila.ac.id ${ }^{3}$, rio.ariestia@eng.unila.ac.id 4
}

\begin{abstract}
Pugung Raharjo archaeological site is the historical tourist destination located in East Lampung. This site keeps the Hinduism-Buddhism civilization which is considered to be the cultural heritage. The rapid development of technology nowadays raises the new digital technology as a media for tourism promotion so that a promotional media through the android-based virtual tour technology must be built. The android-based virtual tour is the proper media to promote Pugung Raharjo archaeological site so that the public recognizes the locations and the historical objects of the site. The feature on this android-based virtual tour is in the 3-dimensional definition. In this research, the MDLC (Multimedia Development Life Cycle) method was necessarily used. The MDLC method was implemented by obtaining the materials, designing the application, creating the application, and distributing the application to the public through a playstore that was able to be downloaded freely. The result of this research showed that this android-based virtual tour was used by the public as a guideline for recognizing the Pugung Raharjo archaeological site.
\end{abstract}

Keywords: Promotion Media, Virtual Tour, 3D, MDLC, Android

\begin{abstract}
Abstrak
Situs Purbakala Pugung Raharjo merupakan destinasi wisata sejarah yang berada di Kabupaten Lampung Timur. Situs ini tersimpan jejak peradaban hindu budha yang sekarang berstatus cagar budaya. Perkembangan zaman yang sangat pesat pada saat ini, telah banyak penggunaan teknologi digital sebagai media promosi wisata. Untuk mempromosikan situs purbakala Pugung Raharjo Lampung Timur kepada masyarakat dalam bentuk digital maka dibuatlah sebuah media promosi dengan teknologi virtual tour berbasis android. Aplikasi virtual tour Situs Purbakala Pugung Raharjo ini digunakan untuk memudahkan masyarakat mengetahui dan mengenal lokasi serta benda-benda bersejarah yang ada di situs purbakala Pugung Raharjo secara virtual 3 dimensi. Pada Penelitian ini menggunakan metode MDLC (Multimedia Development Life Cycle). Metode MDLC ini dimulai dengan mengumpulkan bahan, kemudian membuat sebuah desain dan
\end{abstract}


membuat sebuah aplikasi berdasarkan desain yang telah dibuat sebelumnya. Proses terakhir pembuatan aplikasi ini yaitu distribusi kepada masyarakat melalui playstore yang dapat diunduh secara gratis. Hasil penelitian menunjukkan bahwa aplikasi virtual tour ini dapat digunakan sebagai pedoman masyarakat untuk mengetahui serta mengenal situs purbakala Pugung Raharjo.

Kata kunci : Media promosi, Virtual tour, 3D, MDLC, Android

\section{PENDAHULUAN}

Situs Purbakala Pugung Raharjo memiliki luas 30 hektar yang beralamat di Desa Pugung Raharjo, Kecamatan Sekampung Udik, Kabupaten Lampung Timur. Situs ini merupakan situs purbakala dari zaman megalitikum, ditempat ini tersimpan jejak perkembangan peradaban nusantara yang sekarang berstatus cagar budaya. tempat ini sangat cocok sebagai destinasi wisata sekaligus sebagai edukasi masyarakat yang suka akan sejarah kebudayaan masa lalu. Situs Pugung Raharjo merupakan situs arkeologi yang sudah dikenal masyarakat luas. Meskipun demikian, keberadaan Pugung Raharjo belum dimanfaatkan secara maksimal. Pengelolaan yang tampak di lapangan baru terbatas pada pemeliharaan dan perlindungan. Pihak yang secara langsung berkepentingan dalam pengelolaan dan pemanfaatan adalah instansi dinas pemerintah setempat. Apabila hal ini dibiarkan maka situs Pugung Raharjo akan hanya membebani dan tidak memberikan manfaat yang berarti[1].

Permasalahan atau kondisi saat ini yang terjadi sesuai dengan fakta yang diperoleh di lokasi penelitian adalah belum adanya media promosi digital untuk mengenalkan objek wisata tersebut. Promosi (Promotion) adalah suatu unsur yang digunakan untuk memberitahukan dan membujuk pasar tentang produk atau jasa yang baru pada perusahaan melalui iklan, penjualan pribadi, promosi penjualan, maupun publikasi[2].

Solusi yang bisa dilakukan adalah mengembangan dan memanfaatkan teknologi digital sebagai media promosi dan pemasaran salah satunya yaitu dengan teknologi Virtual Tour berbasis 3D. Virtual Tour adalah simulasi dari sebuah lokasi yang sesungguhnya, umumnya terdiri oleh sequence video atau kumpulan foto[3]. Objek 3 dimensi yang ditampilkan dalam aplikasi virtual tour tersebut agar dapat terwujud maka memerlukan beberapa software seperti google sketchup dan unity. Game engine Unity 3D merupakan sebuah software (perangkat lunak) yang dirancang untuk dapat menciptakan atau mengembangkan Video Game[4]. Google SketchUp adalah program grafis 3D yang dikembangkan oleh Google yang mengombinasikan seperangkat alat (tools) yang sederhana, namun sangat handal dalam desain grafis 3D di dalam layar komputer[5].

Virtual Tour berbasis 3D menyajikan kepada wisatawan bentuk dan kondisi tempat wisata secara virtual. Sehingga diharapkan dapat meningkatkan minat wisatawan untuk berkunjung khususnya di Situs Purbakala Pugung Raharjo Lampung Timur. 


\section{METODOLOGI PENELITIAN}

\subsection{Metode Pengumpulan Data}

Dalam penelitian ini dilakukan pengumpulan data yang dibutuhkan, beberapa metode pengumpulan data yang digunakan yaitu :

a. Wawancara

Wawancara dilakukan kepada pengelola situs purbakala Pugung Raharjo yaitu bapak Rohmat yang beralamat di desa Pugung Raharjo, Kecamatan Sekampung Udik, kabupaten Lampung Timur dan salah satu pengunjung yang tengah berkunjung di situs purbakala Pugung Raharjo.

b. Observasi dan Dokumentasi

Observasi dilakukan dengan cara datang langsung ke lokasi penelitian guna memperoleh fakta-fakta dan kondisi di lokasi penelitian. Dokumentasi yang dilakukan berupa foto-foto, video yang diambil pada saat di lokasi penelitian.

c. Kuesioner

Kuesioner ini dilakukan dengan cara memberikan beberapa pertanyaan kepada responden untuk dijawab, kuesioner ini dibuat untuk menganalisis kebutuhan pengguna yang bertujuan untuk mengetahui seberapa penting aplikasi virtual tour ini dibuat dan digunakan.

\subsection{Metode Pengembangan Multimedia}

Perangkat lunak yang dipakai adalah perangkat lunak multimedia maka dari itu metode pengembangannya pun menggunakan metode pengembangan multimedia. Adapun metode pengembangan multimedia yang dipakai yaitu dengan metode MDLC (Multimedia Development Life Cycle) serta menggunakan UML (Unified Modelling Language). Metode MDLC ini memiliki 6 tahapan yaitu diawali dengan tahapan Concept, Design, Material Collecting, Assembly, Testing dan tahapan terakhir adalah Distribution.

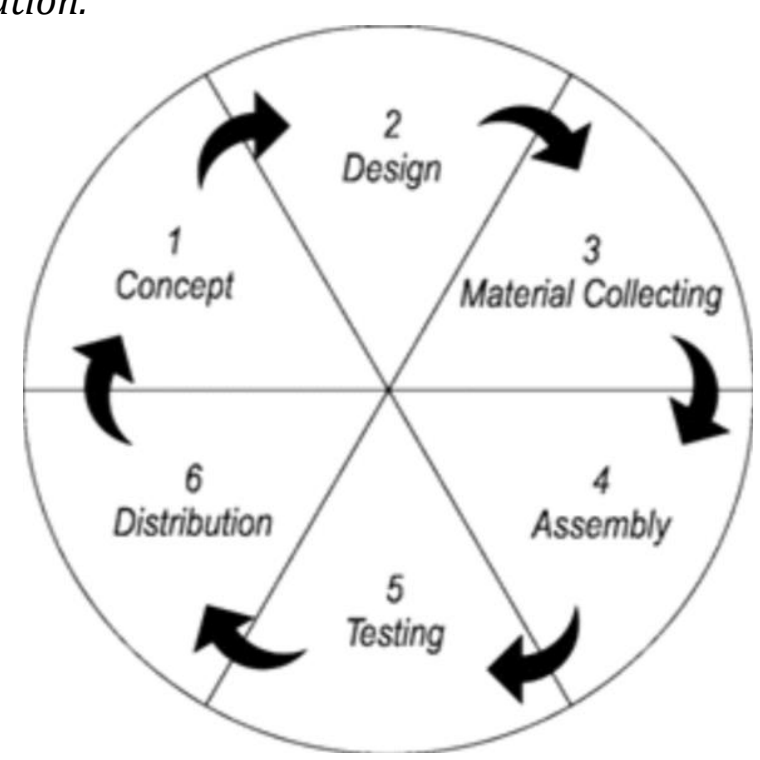

Gambar 1. Tahapan Multimedia Development Live Cycle(MDLC) 


\subsubsection{Concept (Perencanaan)}

Konsep dari aplikasi ini yaitu membangun sebuah aplikasi perjalanan wisata secara virtual atau virtual tour. Aplikasi virtual tour ini berbasis android dengan beberapa tombol navigasi yang diperlukan dan berisi narasi/audio seorang guide.

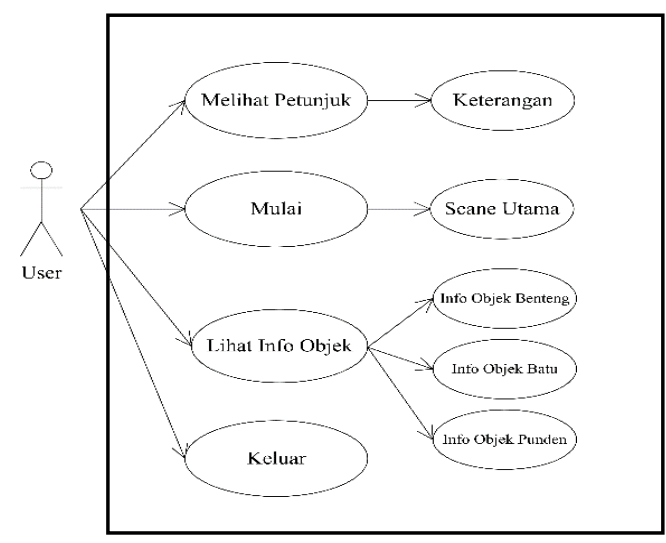

Gambar 2. Use case diagram diusulkan

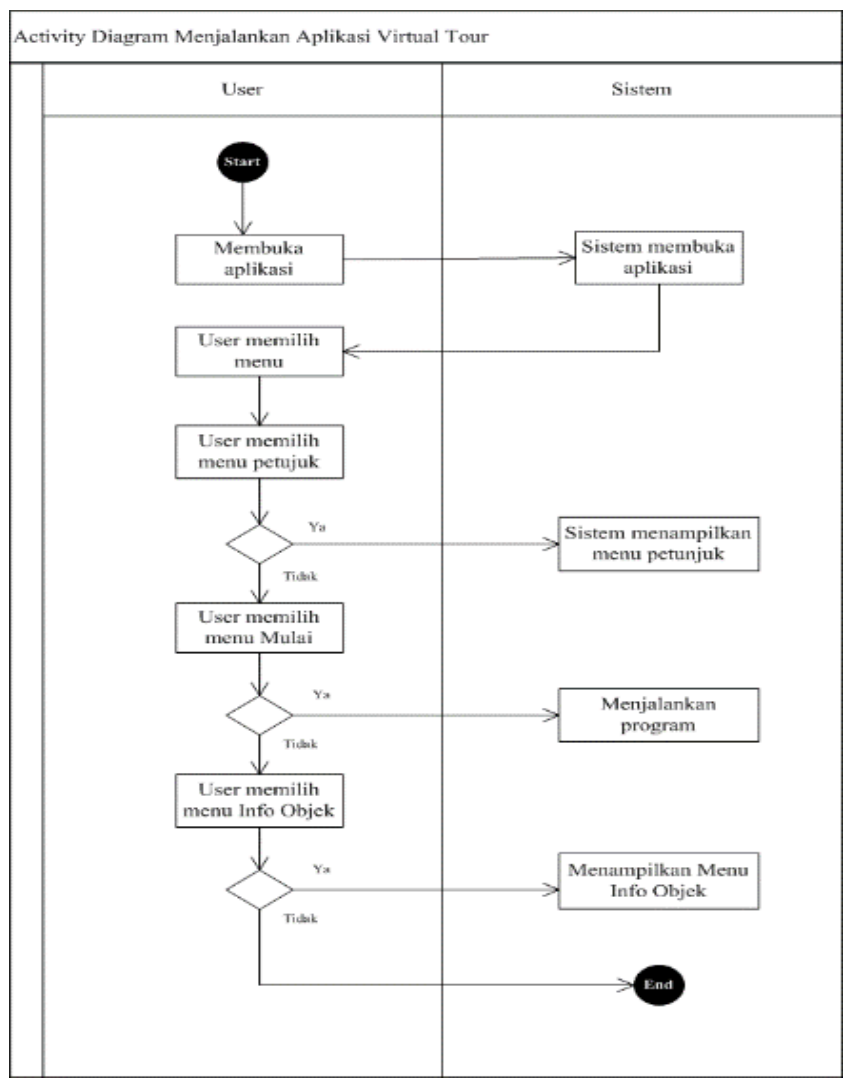

Gambar 3. Activity diagram yang diusulkan 


\subsubsection{Design (Desain)}

Pada tahap desain ini adalah merancang tampilan (interface) dari sebuah aplikasi. Pada tahap perancangan yang dibuat menggunakan metode storyboard. Storyboard adalah metode untuk menjelaskan alur atau jalannya cerita dalam aplikasi. Tujuan daripada penggunaan storyboard adalah untuk menjelaskan kepada user bagaimana aplikasi berjalan dan menggambarkan isi daripada aplikasi yang dibuat. Tahapan desain merupakan pondasi awal terpenting dalam mengembangkan aplikasi ini, karena jika desain sudah matang, maka untuk melakukan tahapan selanjutnya yaitu material collecting, assembly dan testing akan lebih mudah dan akan meminimalisir terjadinya kesalahan

\subsubsection{Material Collecting}

Tahap material collecting yaitu tahap pengumpulan bahan yang diperlukan untuk membuat sebuah aplikasi. Adapun bahan yang diperlukan oleh pengembang adalah mengumpulkan gambar-gambar, foto-foto, peta lokasi, dan file-file pendukung lainnya. Semua bahan yang telah dikumpulkan ini akan digunakan pada tahapan selanjutnya yaitu tahapan assembly.

\subsubsection{Assembly}

Tahap Assembly adalah tahap pembuatan aplikasi dimana semua objek dan semua bahan multimedia dibuat dalam satu aplikasi. Pembuatan aplikasi ini berdasarkan tahap desain yang telah dirancang sebelumnya yang kemudian dibuat di tahap assembly ini. Pada tahapan assembly yang awal biasanya hanya berdasarkan data-data minimal yang dimiliki oleh pengembang, untuk selanjutnya dilakuan pengetesan agar didapat data yang lebih akurat.

\subsubsection{Testing (Pengujian)}

Tahap pengujian dilakukan ketika aplikasi sudah selesai dibuat pada tahap assembly. Melalui metode black box testing pengujian aplikasi dilakukan untuk mengetahui layak atau tidak aplikasi ini dipakai dan diterima atau tidaknya aplikasi ini di kalangan masyarakat untuk sebagai acuan masyarakat agar berkunjung ke situs purbakala Pugung Raharjo.

\subsubsection{Distribution(distribusi)}

Tahapan distribusi dilakukan setelah aplikasi dilakukan testing dan dianggap sudah layak untuk didistribusikan. Tahapan pendistribusian ini dapat dilakukan dengan berbagai cara seperti menyediakan aplikasi di playsotre atau menyediakan dalam bentuk CD. Cara distribusi disesuaikan dengan kebutuhan konsumen.

\section{HASIL DAN PEMBAHASAN}

Berikut ini hasil tampilan dan interface aplikasi virtual tour yang telah dibuat menggunakan unity $3 D$. Tampilan interface aplikasi virtual tour terdiri dari tampilan menu utama, dan tampilan utama aplikasi virtual tour. 


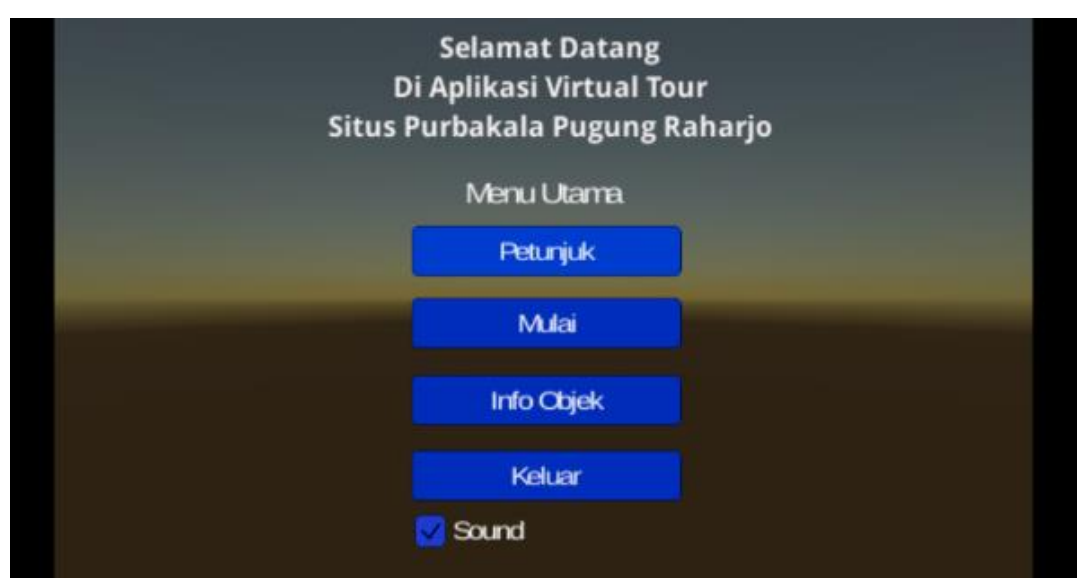

Gambar 4. Halaman Menu Utama

\subsection{Tampilan halaman utama virtual tour}

Halaman utama virtual tour adalah halaman utama aplikasi yang akan digunakan oleh user untuk berjalan dan menjelajahi lingkungan virtual situs purbakala Pugung Raharjo ketika user menekan tombol mulai pada menu utama.

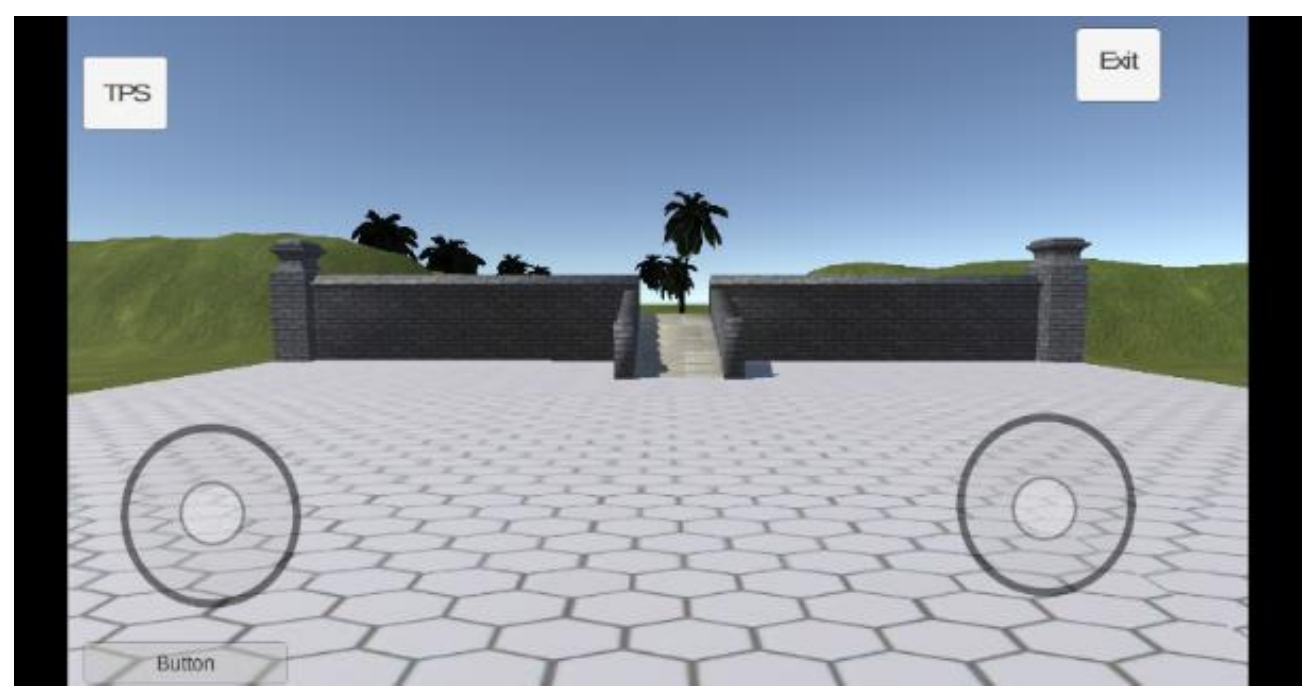

Gambar 5. Tampilan utama virtual tour

\subsection{Tampilan halaman menu info objek}

Tampilan halaman menu info objek adalah halaman menu untuk memilih info objek. Terdapat tombol info objek benteng, info objek batu mayat, info objek punden. 


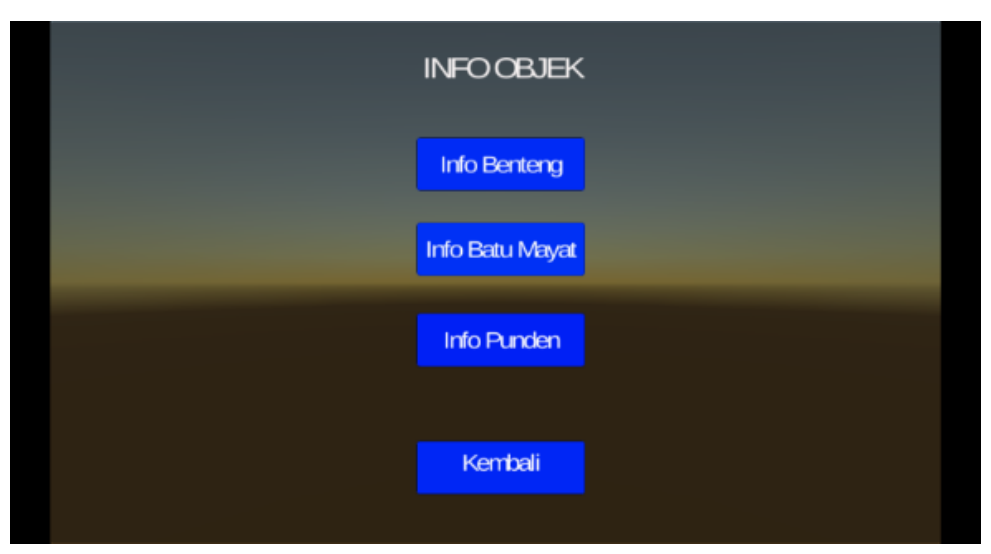

Gambar 6. Tampilan halaman menu info objek

\subsection{Tampilan halaman menu info objek benteng tanah}

Tampilan halaman menu info objek benteng tanah berisi informasi tentang objek benteng tanah yang terdiri dari gambar, teks, dan audio.

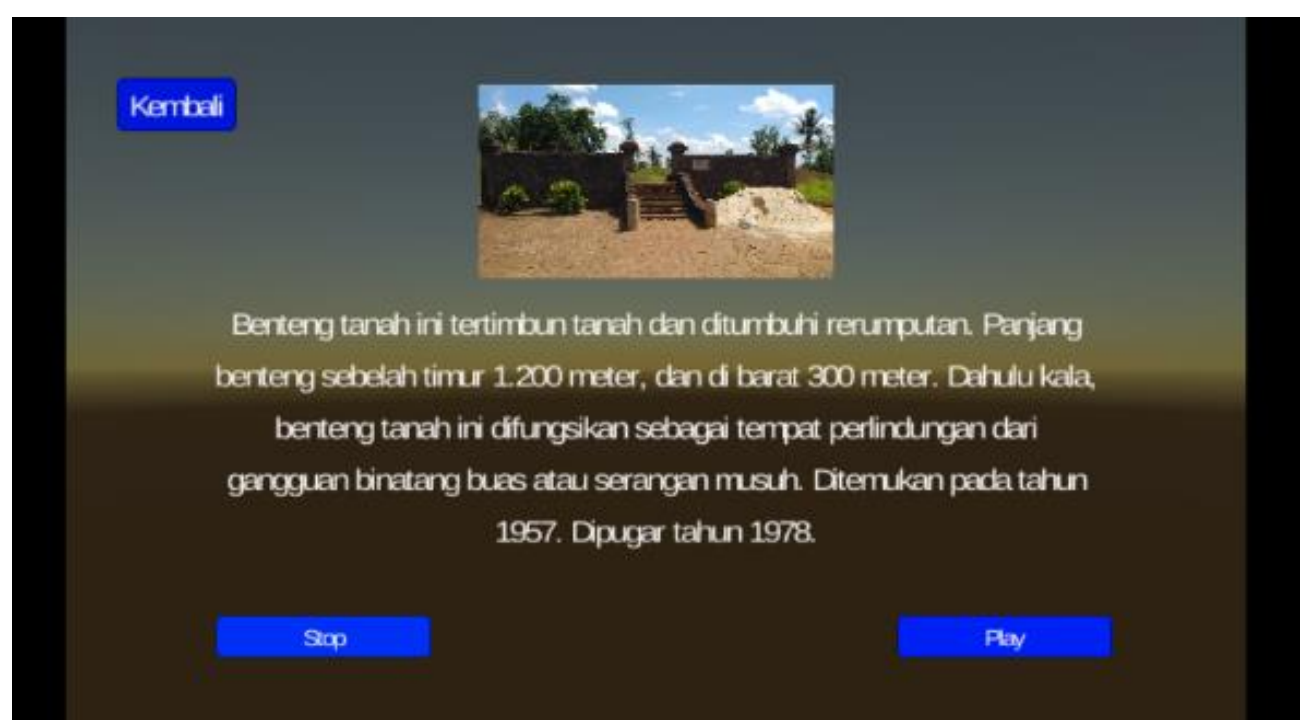

Gambar . 7 Tampilan halaman menu info objek Benteng Tanah

\subsection{Tampilah halaman menu info objek batu mayat}

Tampilan halaman menu info objek batu mayat berisi informasi tentang objek komplek batu mayat yang terdiri dari gambar, teks, dan audio. 


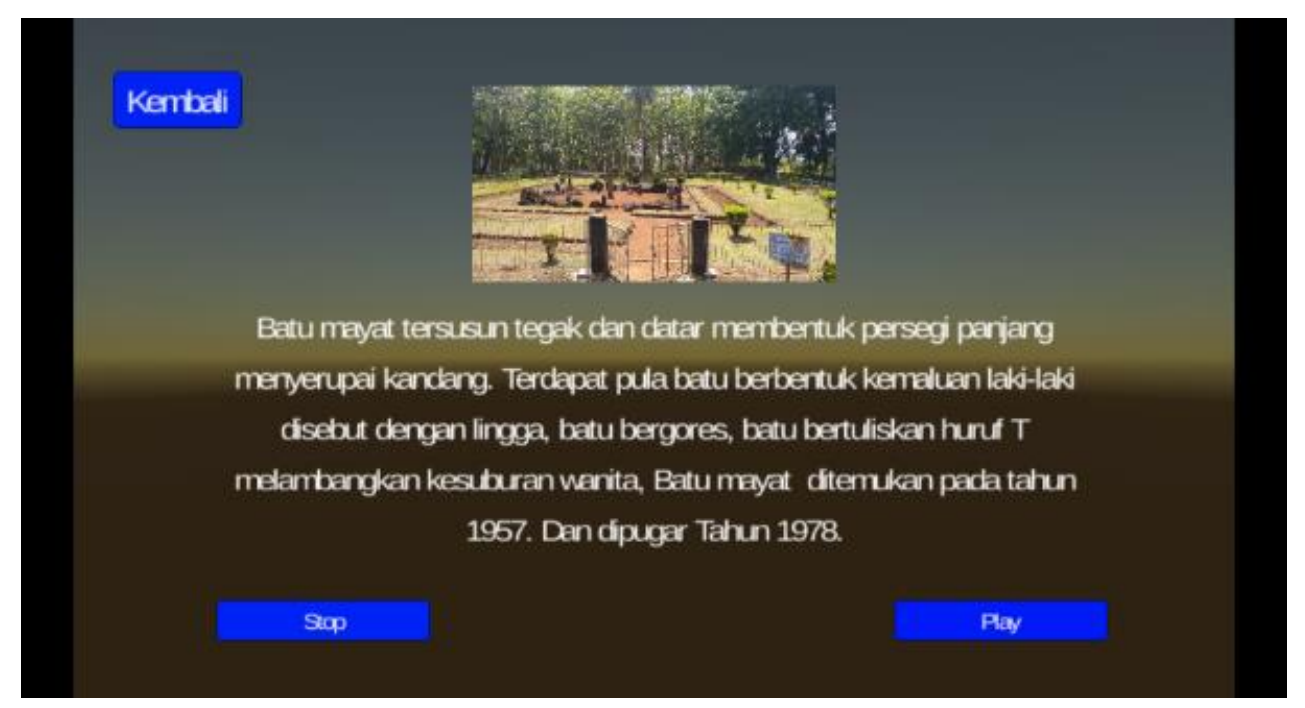

Gambar 8. Tampilan halaman menu info objek Batu Mayat

3.5 Tampilan halaman menu info objek punden

Tampilan halaman menu info objek punden berisi informasi tentang objek punden berundak yang terdiri dari gambar, teks, dan audio.

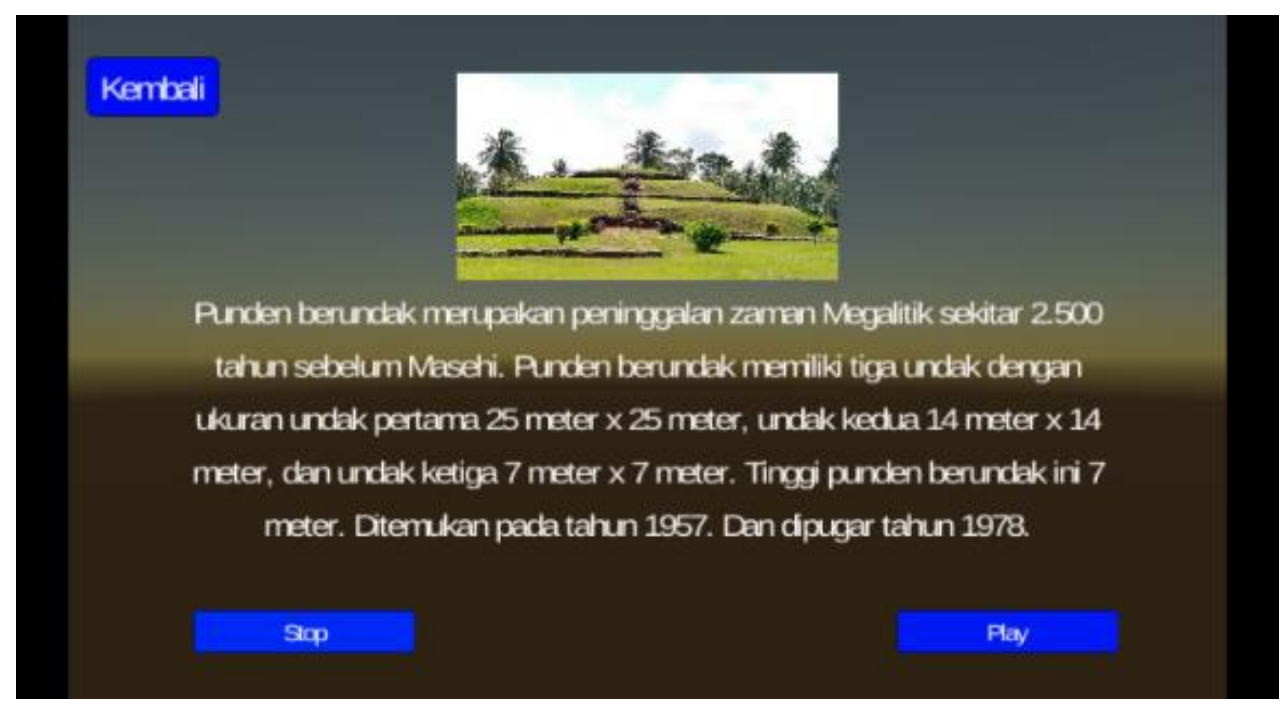

Gambar 9. Tampilan halaman menu info objek Punden

\section{SIMPULAN}

Berdasarkan latar belakang dan pembahasan yang telah dibahas pada babbab sebelumnya, maka dapat disimpulkan :

a. Aplikasi virtual tour 3D Situs Purbakala Pugung Raharjo yang telah dibuat dapat digunakan sebagai media promosi objek wisata situs purbakala Pugung Raharjo kabupaten Lampung Timur. 
b. Aplikasi virtual tour 3D Situs Purbakala Pugung Raharjo ini dibuat sesuai dengan rancangan, yaitu dapat menampilkan objek $3 D$ dan informasi berupa teks dan audio yang bertujuan untuk memberikan informasi tentang situs purbakala Pugung Raharjo kepada user.

c. Aplikasi virtual tour Situs Purbakala Pugung Raharjo ini dapat di install kedalam perangkat android dan dapat di download di playstore.

d. Hasil pengujian black box yang dilakukan menunjukkan bahwa semua pengujian berjalan baik dan tidak ada kendala yang berarti

\section{DAFTAR PUSTAKA}

[1] N. Saptono, "Situs Pugung Raharjo dalam Konteks Pengembangan Pariwisata," PURBAWIDYA J. Penelit. dan Pengemb. Arkeol., 2016, doi: 10.24164/pw.v1i2.60.

[2] Kotler, Principals of marketing. 2014.

[3] M. Colasante, "Nicola building virtual tour; considering simulation in the equity of experience concept," 2011.

[4] N. Yulianto, "PEMBUATAN GAME 3 DIMENSI LOST IN THE JUNGLE DENGAN MENGGUNAKAN UNITY 3D GAME ENGINE," 2012.

[5] S. I. A. Setiawan, "Google SketchUp Perangkat Alternatif dalam Pemodelan 3D," J. Ultim., 2011, doi: 10.31937/ti.v3i2.298. 